\title{
Chronic graft-versus-host disease in children: incidence, risk factors, and impact on outcome
}

Marco Zecca, Arcangelo Prete, Roberto Rondelli, Edoardo Lanino, Adriana Balduzzi, Chiara Messina, Franca Fagioli, Fulvio Porta, Claudio Favre, Andrea Pession, and Franco Locatelli, on behalf of the AIEOP-BMT Group

\begin{abstract}
Chronic graft-versus-host disease (cGVHD) remains the major cause of late morbidity and mortality after allogeneic hematopoietic stem cell transplantation (HSCT). However, only a few studies specifically focused on children, and little information is available on the antileukemic effect of CGVHD and its impact on diseasefree survival (DFS) in children. We retrospectively analyzed 696 children given allogeneic HSCT for malignant $(n=450)$ or nonmalignant $(n=246)$ diseases. The donor was an HLA-identical sibling in 461 cases and an alternative donor in 235. Bone marrow was the stem cell source in 647 cases, peripheral blood
\end{abstract}

in 17 , and cord blood (CB) in 32. cGVHD developed in 173 children (25\%) at a median of 116 days after HSCT. Three-year cGVHD probability was $27 \%$. In multivariate analysis, variables predicting cGVHD were donor and recipient age, grade II to IV acute GVHD, female donor for male recipient, diagnosis of malignancy, and use of total body irradiation; $C B$ transplants had a very low risk of CGVHD (RR $=0.07, P=.0001)$. cGVHD occurrence increased transplant-related mortality $(P<.05)$. Nevertheless, in hematologic malignancies, patients with cGVHD had a reduced relapse probability compared with children without cGVHD
$(16 \% \pm 3 \%$ versus $39 \% \pm 3 \%, P=.0001)$ and a better DFS $(68 \% \pm 4 \%$ versus $54 \% \pm 3 \%, P=.01)$. The antileukemic effect of cGVHD was observed mainly in patients with acute lymphoblastic leukemia (ALL). This study provides novel data on cGVHD in childhood. Use of CB stem cells and preparative regimens without radiotherapy may prevent its development. In patients affected by ALL, cGVHD was associated with a strong graft-versusleukemia effect, improving DFS. (Blood. 2002;100:1192-1200)

๑) 2002 by The American Society of Hematology

\section{Introduction}

Chronic graft-versus-host disease (cGVHD) remains the most frequent late complication after allogeneic hematopoietic stem cell transplantation (HSCT) and it represents the major cause of nonrelapse mortality and morbidity in long-term survivors. ${ }^{1-3}$ In adults, the reported incidence of cGVHD ranges between $30 \%$ and $50 \%$ of HLA-identical sibling transplant recipients, ${ }^{1}$ with acute GVHD being recognized as the most important factor predicting the development of the chronic form of the disease. ${ }^{4-6}$ The increased use of matched unrelated volunteers as donors ${ }^{7}$ and of peripheral blood as a stem cell source ${ }^{8,9}$ has led to a further increase of the incidence and severity of this complication.

Chronic GVHD is associated with a graft-versus-leukemia effect (GVL), thus resulting, in the context of transplantation for the treatment of hematologic malignancies, in a decreased incidence of relapse. ${ }^{10-12}$ Nevertheless, the reduced relapse rate could be offset by an increase in transplant-related mortality (TRM) and counterbalanced by a severely impaired quality of life for patients experiencing the extensive form of the disease. ${ }^{2,3}$

Previously published studies documented a lower risk of cGVHD, as well as of acute GVHD, in younger patients. ${ }^{4-6}$

From Oncoematologia Pediatrica, Università di Pavia, IRCCS Policlinico San Matteo, Pavia, Italy; Clinica Pediatrica, Università di Bologna, Policlinico Sant'Orsola, Bologna, Italy; Oncoematologia Pediatrica, Ospedale G. Gaslini, Genova, Italy; Clinica Pediatrica, Università di Milano Bicocca, Ospedale San Gerardo, Monza, Italy; Oncoematologia Pediatrica, Dipartimento di Pediatria, Università di Padova, Padova, Italy; Clinica Pediatrica, Ospedale Regina Margherita, Università di Torino, Torino, Italy; Clinica Pediatrica, Spedali Civili, Università di Brescia, Brescia, Italy; Clinica Pediatrica, Università di Pisa, Pisa, Italy.

Submitted November 28, 2001; accepted April 3, 2002. Prepublished online as Blood First Edition Paper, May 17, 2002; DOI 10.1182/blood-2001-11-0059.

Partly supported by grants from Associazione Italiana Ricerca sul Cancro
However, only a few studies specifically focused on children. ${ }^{13-15}$ For this reason, risk factors for cGVHD in childhood are still poorly defined, and little information is available on the GVL effect of this complication, as well as on its impact on disease-free survival (DFS) and TRM of young patients.

We carried out a retrospective analysis on a large number of children receiving allogeneic HSCT from either a matched or mismatched family donor or an unrelated volunteer, to identify risk factors predicting the development of cGVHD and to assess its impact on clinical outcome.

\section{Patients and methods}

\section{Patient characteristics}

A total of 696 consecutive patients, undergoing allogeneic HSCT between January 1, 1991, and June 30, 1999, in one of the transplantation centers of the Italian Association for Pediatric Hematology and Oncology (AIEOP) and reported to the AIEOP-BMT Registry were included in this analysis. All new transplantations performed were registered yearly by each center,

(AIRC), Consiglio Nazionale delle Ricerche (CNR), Ministero dell'Università e della Ricerca Scientifica e Tecnologica (MURST), and Istituto di Ricovero Cura a Carattere Scientifico (IRCCS) Policlinico S. Matteo to F.L. and by a grant from IRCCS Policlinico San Matteo to M.Z.

M.Z. and A.P. contributed equally to this work.

Reprints: Marco Zecca, Oncoematologia Pediatrica, IRCCS Policlinico San Matteo, P.le Golgi, 2, I-27100 Pavia, Italy; e-mail: m.zecca@smatteo.pv.it.

The publication costs of this article were defrayed in part by page charge payment. Therefore, and solely to indicate this fact, this article is hereby marked "advertisement" in accordance with 18 U.S.C. section 1734

(c) 2002 by The American Society of Hematology 
together with the updated follow-up of previously reported transplantations, through disease- and transplant-specific data collection forms.

For the purpose of this study, only patients younger than 18 years of age at the time of HSCT and surviving more than 90 days after the graft were considered for data analysis. Exclusion criteria for the definition of the study population comprised second or subsequent transplantations, the use of a genotypically identical twin as donor, and a diagnosis of solid tumor.

In all donor-recipient pairs, histocompatibility was determined by serology for HLA-A, B, and DR antigens, whereas high-resolution molecular typing of HLA-class II DRB1 was available for all children undergoing HSCT from an unrelated donor. A total of 450 children (65\%) had hematologic malignancies; the other 246 children $(35 \%)$ had a nonmalignant disorder. Children with acute leukemia receiving transplants during first or second complete remission, those with myelodysplastic syndrome (MDS) characterized by a low blast count (ie, refractory anemia and refractory anemia with ringed sideroblasts), as well as patients with chronic myeloid leukemia (CML) in first chronic phase were considered in early phase, whereas all other patients with leukemia or MDS were considered in advanced phase. Of the 696 patients analyzed, 418 were boys and 278 girls. Median age at transplantation was 7 years (range, 0.3-17 years), whereas median donor age was 12 years (range, $0-55$ years). The donor was an HLA-identical sibling in 461 cases $(66 \%)$, a partially matched family donor in 68 cases (10\%), and an unrelated volunteer in the remaining 167 patients (24\%). The source of stem cells was bone marrow in 647 cases (93\%), peripheral blood in $17(2 \%)$, and cord blood $(\mathrm{CB})$ in $32(5 \%)$. GVHD prophylaxis consisted of cyclosporin A (Cs-A) alone in 343 cases (49\%) and Cs-A in combination either with methotrexate (MTX) in 127 cases $(18 \%)$ or with steroids (prednisone [PDN]) in 62 cases (9\%). The combination of Cs-A + MTX + in vivo serotherapy (antilymphocyte globulin $[\mathrm{ALG}]$ or the monoclonal antibody [mAb] Campath-1G) was adopted for 102 transplants (15\%). Nineteen patients (3\%) received a T-cell-depleted HSCT.

Details on the 696 patients evaluated, as well as on the transplantation procedure, are reported in Table 1.

\section{Diagnosis of acute and chronic GVHD and of chronic GVHD resolution}

The diagnosis of acute and cGVHD was made by the site investigators at each institution on the basis of clinical symptoms, laboratory tests, and, whenever possible, on histopathologic findings of skin, oral mucosa, and gastrointestinal tract. ${ }^{16-18}$ Acute and cGVHD were classified according to previously described criteria. ${ }^{19,20}$ Limited cGVHD was defined as either or both localized skin involvement and hepatic dysfunction due to chronic GVHD; extensive cGVHD was defined as generalized skin involvement, or localized skin involvement or hepatic dysfunction due to cGVHD plus liver histology showing chronic aggressive hepatitis, bridging necrosis or cirrhosis, or involvement of the eye or minor salivary glands or oral mucosa, or involvement or any other target organ..$^{20,21}$

Resolution of cGVHD was defined as the disappearance of all active lesions attributable to cGVHD (whenever possible confirmed by histopathologic findings) or normalization of liver function tests, associated with the discontinuation of any form of immunosuppressive treatment.

\section{Treatment of chronic GVHD}

The choice among the different options for treatment of cGVHD was based on the policy in use in each single transplantation center and varied over time. Thirty-three children received a single drug treatment (Cs-A alone in 20 cases, PDN alone in 11, ursodeoxycholic acid in 1, and mAbs in 1), whereas the standard combination of Cs-A and PDN was used in 62 children, with the addition of azathioprine in 14. Thalidomide was used, always in combination with Cs-A or steroids, in 14 patients. Fifteen children received 3 or more immunosuppressive drugs. Extracorporeal photochemotherapy was used, as single treatment modality or in combination with other systemic immunosuppressive drugs, in 26 children. $^{22,23}$
Table 1. Patient characteristics

\begin{tabular}{|c|c|c|}
\hline Characteristics and treatments & Number & Percentages \\
\hline Number of patients & 696 & \\
\hline Sex, M/F & $418 / 278$ & $60 / 40$ \\
\hline Median age at transplantation, y (range) & $7(0.3-17)$ & \\
\hline \multicolumn{3}{|l|}{ Diagnosis } \\
\hline Malignant disease & 450 & 65 \\
\hline ALL & 268 & 38 \\
\hline AML & 99 & 14 \\
\hline $\mathrm{CML}$ & 28 & 5 \\
\hline MDS & 36 & 5 \\
\hline Lymphoma & 19 & 3 \\
\hline Nonmalignant disease & 246 & 35 \\
\hline Thalassemia & 88 & 12 \\
\hline Severe aplastic anemia & 35 & 5 \\
\hline Fanconi anemia & 23 & 3 \\
\hline Immunodeficiencies & 48 & 7 \\
\hline Inborn errors & 52 & 8 \\
\hline \multicolumn{3}{|l|}{ Donor } \\
\hline HLA-identical family donor & 461 & 66 \\
\hline Partially matched family donor & 68 & 10 \\
\hline HLA-identical unrelated donor & 141 & 20 \\
\hline Partially matched unrelated donor & 26 & 4 \\
\hline Female donor/male recipient pairs & 196 & 28 \\
\hline Median donor age, y (range) & $12(0-55)$ & \\
\hline \multicolumn{3}{|l|}{ Stem cell source } \\
\hline Bone marrow & 647 & 93 \\
\hline Peripheral blood & 17 & 2 \\
\hline Cord blood & 32 & 5 \\
\hline \multicolumn{3}{|l|}{ Conditioning regimen } \\
\hline Chemotherapy based & 369 & 53 \\
\hline TBI based & 327 & 47 \\
\hline \multicolumn{3}{|l|}{ GVHD prophylaxis } \\
\hline Cs-A & 348 & 50 \\
\hline Cs-A + MTX & 129 & 19 \\
\hline Cs-A + PDN & 63 & 9 \\
\hline Cs-A + MTX + ALG or mAb & 104 & 15 \\
\hline $\mathrm{Cs}-\mathrm{A}+\mathrm{ALG}$ or $\mathrm{mAb} \pm \mathrm{PDN}$ & 33 & 5 \\
\hline T-cell depletion & 19 & 2 \\
\hline \multicolumn{3}{|l|}{ Acute GVHD } \\
\hline Grade 0-I & 406 & 58 \\
\hline Grade II-IV & 290 & 42 \\
\hline
\end{tabular}

Finally, 9 children, all with limited cGVHD, did not need any specific immunosuppressive therapy.

\section{Statistical analysis}

The occurrence of cGVHD, as well as DFS, TRM, and relapse probability according to cGVHD occurrence and extension, were calculated by the Kaplan-Meier method; comparisons between probabilities in different patient groups were performed using the log-rank test. ${ }^{24}$ As suggested by Pepe et al, ${ }^{25}$ cGVHD was presented, besides the Kaplan-Meier curve, also as the prevalence of cGVHD over time after transplantation (Figure 1B). The prevalence function at time $t$ was calculated using the following function: (number of patients with cGVHD at time $t$ )/(number of patients alive and relapse-free at time $t){ }^{25,26}$

In DFS analysis, both relapse and death in remission due to any cause were considered events, whereas in relapse probability analysis, only disease relapse was considered as failure. In TRM analysis, all deaths not due to disease recurrence were considered events. Results were expressed as probability (\%) and 95\% CI. 

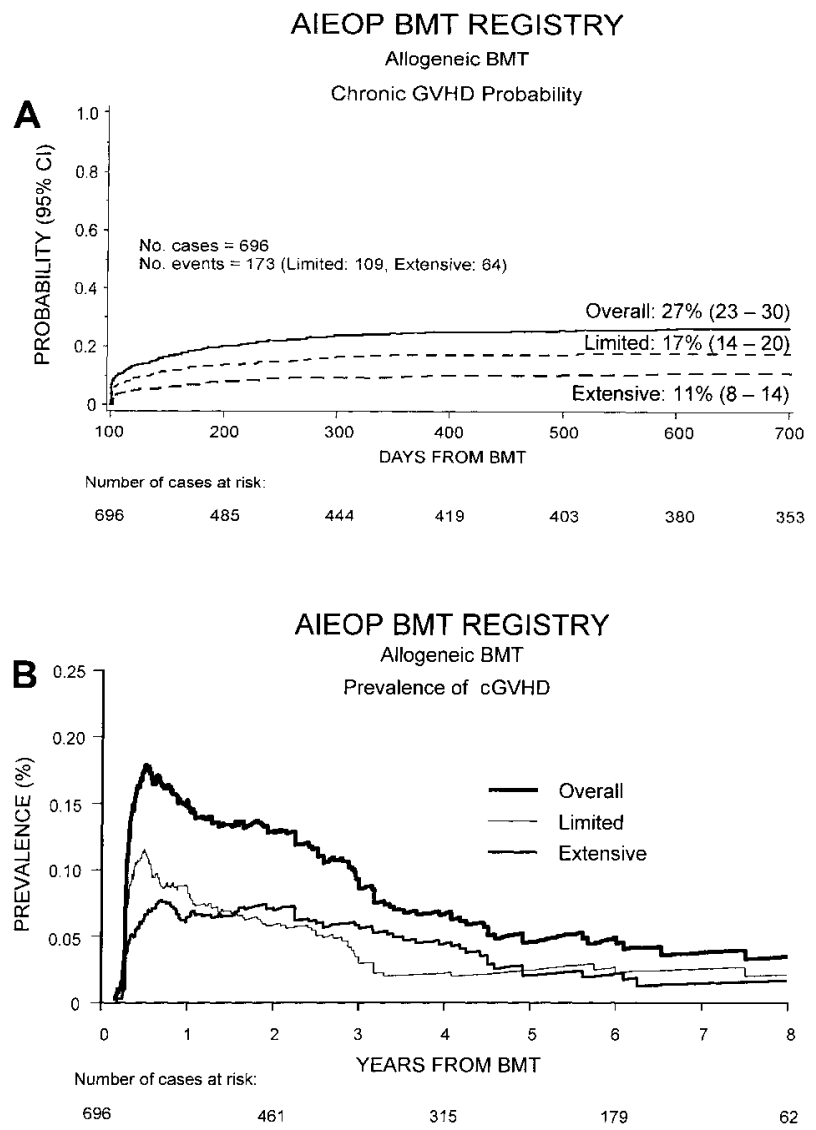

Figure 1. Cumulative probability of developing cGVHD and its prevalence. (A) Overall cumulative probability to develop cGVHD after HSCT in our study population and probability to develop the limited or the extensive form of the disease. (B) Overall prevalence of cGVHD and prevalence of the limited and extensive form of the disease. The prevalence function at time $t$ was calculated using the following function: (number of patients with cGVHD at time $t$ )/(number of patients alive and relapse-free at time $t$ ).

A univariate analysis of DFS, relapse probability, and TRM according to cGVHD occurrence and severity was performed for the whole study population and, subsequently, stratified for malignant and nonmalignant disorders. Furthermore, a separate analysis on the impact of cGVHD on relapse probability and DFS was performed also for the 4 types of hematologic malignancies including the larger number of patients: acute lymphoblastic leukemia (ALL; 268 patients), acute myelogenous leukemia (AML; 99 patients), CML (28 patients), and MDS (36 patients).

In the univariate analysis of risk factors for cGVHD development, the following variables were evaluated: patient and donor age, sex mismatch, parity of female donors, diagnosis, type of donor, stem cell source, use of total body irradiation (TBI) as part of the conditioning regimen, GVHD prophylaxis, infused cell dose, and development of grade II to IV acute GVHD. For this purpose, continuous variables were categorized as follows: each variable was first divided into 4 categories at approximately the 25 th, 50th, and 75th percentiles. If the relative event rates (ratio of the observed number of events to the expected number of events in a category, assuming no variation across categories) in 2 or more adjacent categories (and the mean times-to-event) were not substantially different, these categories were grouped together. If no clear pattern was observed for the primary outcome, the median was taken as the cut point. ${ }^{27}$

For the multivariate analysis of cGVHD, DFS, and relapse probability, the Cox proportional hazard regression model was used, including in the models all the variables with $P<.05$ in univariate analysis..$^{28,29}$

The $\chi^{2}$ test was used to compare differences in percentages.

All $P$ values were 2 -sided and $P<.05$ was considered statistically significant. $P>.1$ was reported as not significant (NS), whereas $P$ between .05 and .1 was reported in detail.

The SAS package (SAS Institute, Cary, NC) was used for the analysis of the data.

\section{Results}

Data were analyzed as of December 31, 2000. Median follow-up was 57 months (range, 18-119 months) for surviving patients and 9 months (range, 3.4-85 months) for patients not surviving.

\section{Incidence of chronic GVHD and chronic GVHD resolution}

Of the 696 patients analyzed, 173 (25\%) developed cGVHD at a median of 116 days after transplantation (range, 80-600 days). The limited form of the disease was observed in 109 patients (16\%), and extensive cGVHD was diagnosed in 64 cases (9\%). As shown in Figure 1A, 2 years after the transplantation, the overall cumulative probability of cGVHD was $27 \%$ (95\% CI, 23\%-30\%). The cumulative probabilities of developing either limited or cGVHD were $17 \%$ (95\% CI, 14\%-20\%) and $11 \%$ (95\% CI, 8\%-14\%), respectively.

For patients with cGVHD, median Karnofsky score at time of last follow-up was $90 \%$, with 72 of the 173 patients (42\%) having a Karnofsky score of $100 \%$ and only 7 (4\%) with a Karnofsky score below $50 \%$.

The skin was the most common target of cGVHD, being involved in 144 cases ( $83 \%$ ); the liver was involved in 49 patients (28\%) and the gastrointestinal tract in 42 (24\%). Oral cGVHD was described in 12 patients (7\%); both eye involvement and joint contractures were reported in 6 cases (3\%). Finally, 19 children $(11 \%)$ had lung involvement from cGVHD.

Figure 1B shows the prevalence of cGVHD over time after HSCT. Prevalence was greater during the first year after HSCT, when it reached a value of $18 \%$, and progressively decreased to about $5 \%$ at 7 years after transplantation. The prevalence of limited cGVHD was greater than that of extensive cGVHD during the first 20 months after HSCT, whereas the prevalence of extensive cGVHD was higher than that of limited cGVHD from 20 months afterward.

Chronic GVHD resolved in 121 patients (70\%), whereas it was still present at the time of last follow-up or at time of death in the remaining 52 children (30\%). The median duration of cGVHD, in the 121 patients in whom this complication resolved, was 5 months (range, 1-93 months).

Figure 2 shows the cumulative probability of continuing cGVHD, which was equal to $16 \%$ (95\% CI, 6\%-25\%) 8 years after transplantation, and the probability of death with cGVHD over time after development of the complication, which was $12 \%(95 \%$ CI, 3\%-18\%).

The analysis concerning the impact of cGVHD therapy on the probability of cGVHD resolution and on patient outcome did not show any statistically significant difference among the different treatment modalities (data not shown).

\section{Risk factors for chronic GVHD}

A number of demographic and transplant-related characteristics were evaluated as potential risk factors for cGVHD. Tables 2 and 3 


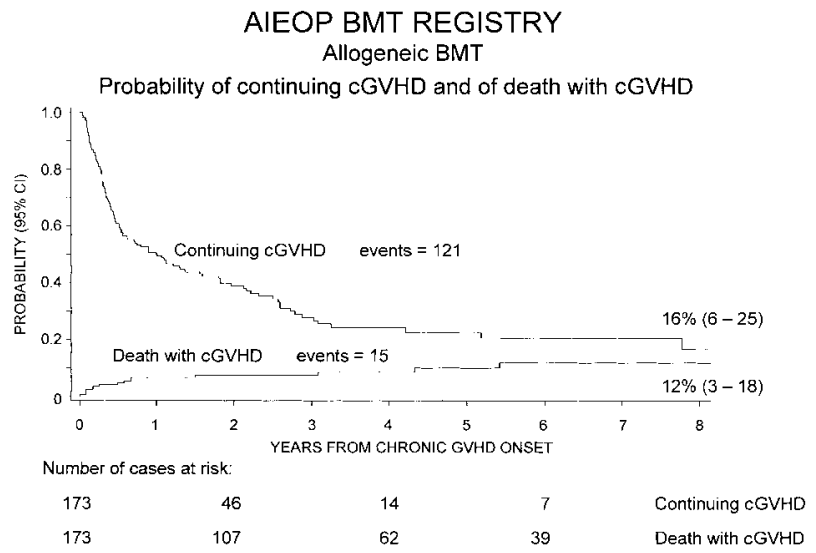

Figure 2. Cumulative probability of continuing cGVHD and of death with cGVHD over time after the onset of cGVHD. To calculate the probability of continuing cGVHD, cGVHD resolutions were considered as events, whereas patients whose cGVHD did not resolve were censored at time of last follow-up or of death. To calculate the probability of death with cGVHD, only deaths with active cGVHD were considered events, whereas patients whose cGVHD resolved were censored time of last follow-up or death.

present the results of univariate and multivariate analysis of risk factors for development of cGVHD.

Several variables were strongly associated with an increased risk of cGVHD in univariate analysis. In particular, older patient age was significantly associated with cGVHD, with children younger than 5 years having a probability of less than $14 \%$ of developing this complication, those aged 5 to 15 years a probability of about $30 \%$, and those older than 15 years a probability of $44 \%$ $(P=.0001)$. Also donor age was a significant risk factor for cGVHD occurrence in univariate analysis, with a continuous increase in the incidence of this complication from less than $10 \%$ for donors younger than 5 years, to more than $40 \%$ for donors older than 40 years of age $(P=.0002)$. Female donor and male recipient combination was another factor predicting cGVHD development (34\% versus $23 \%, P=.01$ ). Furthermore, patients affected by hematologic malignancies had a greater incidence of cGVHD (35\% versus $13 \%, P=.01)$, as well as those treated with TBI (38\% versus $17 \%$, $P=.0001)$ and those with previous grade II to IV acute GVHD (45\% versus $14 \%, P=.0001)$. CB transplants had a significantly lower probability of cGVHD (3\%) compared with bone marrow or peripheral blood transplants $(28 \%, P=.0073)$. As reported in Table 2 , in our cohort of patients, parity of female donors did not show any effect on the risk of cGVHD development.

In multivariate analysis, the following 6 characteristics were associated with an increased probability of developing cGVHD: patient age 15 years or older $(\mathrm{RR}=1.82, P=.03)$, donor age 5 years or older $(\mathrm{RR}=3.36, P<.001)$, female donor and male recipient $(\mathrm{RR}=1.52, P=.01)$, use of TBI as part of the conditioning regimen $(\mathrm{RR}=1.56, P=.02)$, diagnosis of hematologic malignancy $(\mathrm{RR}=1.80, P=.01)$, and, with the highest relative risk, previous grade II to IV acute GVHD $(\mathrm{RR}=2.14, P=.0001)$. On the contrary, transplants of CB stem cells were characterized by a very low incidence of cGVHD, with only 1 child of 32 presenting this complication $(\mathrm{RR}=0.07, P=.001)$.

\section{Causes of death and TRM}

Overall, 191 (27\%) of the 696 patients analyzed died; $146(28 \%)$ belonged to the group of 523 subjects without cGVHD, whereas 45 (26\%) belonged to the 173 children with cGVHD.

Details on the causes of death for patients with and without cGVHD are reported in Table 4. Disease progression was the main
Table 2. Univariate analysis of risk factors for cGVHD development

\begin{tabular}{|c|c|c|c|c|c|}
\hline & \multicolumn{5}{|c|}{ Univariate analysis } \\
\hline & $\begin{array}{l}\text { No. of } \\
\text { cases }\end{array}$ & Events & $\begin{array}{c}\text { Probability, } \\
\%\end{array}$ & $(95 \% \mathrm{Cl})$ & $P$ \\
\hline \multicolumn{6}{|l|}{ Patient age } \\
\hline Younger than $2 \mathrm{y}$ & 108 & 9 & 9 & $(3-14)$ & .0001 \\
\hline $2-5 y$ & 122 & 27 & 14 & $(16-31)$ & \\
\hline $5-10 y$ & 239 & 67 & 30 & $(24-36)$ & \\
\hline $10-15 y$ & 170 & 46 & 29 & $(22-37)$ & \\
\hline 15 y or older & 57 & 24 & 44 & $(31-58)$ & \\
\hline \multicolumn{6}{|l|}{ Donor age } \\
\hline Younger than $2 \mathrm{y}$ & 49 & 2 & 4 & $(0-10)$ & .0002 \\
\hline $2-5 y$ & 84 & 8 & 10 & $(3-16)$ & \\
\hline $5-10 y$ & 139 & 32 & 25 & $(17-32)$ & \\
\hline $10-15 y$ & 100 & 26 & 27 & $(18-36)$ & \\
\hline $15-20 y$ & 75 & 21 & 30 & $(19-40)$ & \\
\hline $20-30 y$ & 96 & 30 & 36 & $(25-46)$ & \\
\hline $30-40 y$ & 96 & 31 & 39 & $(29-49)$ & \\
\hline 40 y or older & 49 & 19 & 42 & $(27-57)$ & \\
\hline Unknown & 8 & 4 & & & \\
\hline \multicolumn{6}{|l|}{ Sex } \\
\hline \multicolumn{6}{|l|}{ Female donor and male } \\
\hline recipient & 196 & 62 & 34 & $(27-41)$ & .01 \\
\hline Other & 497 & 109 & 23 & $(20-27)$ & \\
\hline Unknown & 3 & 2 & & & \\
\hline \multicolumn{6}{|l|}{ Parity $^{*}$} \\
\hline Female donor, no pregnancy & 34 & 18 & 58 & $(40-76)$ & NS \\
\hline \multicolumn{6}{|l|}{ Female donor, 1 or more } \\
\hline pregnancies & 37 & 15 & 44 & $(27-61)$ & \\
\hline \multicolumn{6}{|l|}{ Diagnosis } \\
\hline Nonmalignant disease & 246 & 31 & 13 & $(9-17)$ & .001 \\
\hline Malignant disease & 450 & 142 & 35 & $(30-39)$ & \\
\hline \multicolumn{6}{|l|}{ Donor } \\
\hline HLA-identical family & 461 & 105 & 24 & $(20-28)$ & .019 \\
\hline Partially matched family & 68 & 15 & 27 & $(15-39)$ & \\
\hline HLA-identical unrelated & 141 & 48 & 37 & $(29-46)$ & \\
\hline Partially matched unrelated & 26 & 5 & 20 & $(4-35)$ & \\
\hline \multicolumn{6}{|l|}{ Stem cell source } \\
\hline Bone marrow & 647 & 168 & 28 & $(24-31)$ & .027 \\
\hline Peripheral blood & 17 & 4 & 30 & $(4-55)$ & \\
\hline Cord blood & 32 & 1 & 3 & $(0-9)$ & \\
\hline \multicolumn{6}{|l|}{ Stem cell source } \\
\hline \multicolumn{6}{|l|}{ Bone marrow + peripheral } \\
\hline blood & 664 & 172 & 28 & $(24-31)$ & .0073 \\
\hline Cord blood & 32 & 1 & 3 & $(0-9)$ & \\
\hline \multicolumn{6}{|l|}{ Conditioning regimen } \\
\hline Chemotherapy based & 369 & 60 & 17 & $(13-21)$ & .0001 \\
\hline TBI based & 327 & 113 & 38 & $(33-44)$ & \\
\hline \multicolumn{6}{|l|}{ GVHD prophylaxis } \\
\hline Cs-A & 348 & 82 & 25 & $(20-30)$ & .0052 \\
\hline Cs-A + MTX & 129 & 32 & 27 & $(19-35)$ & \\
\hline Cs-A + PDN & 63 & 13 & 23 & $(12-34)$ & \\
\hline Cs-A + MTX + ALG or mAb & 104 & 39 & 42 & $(31-42)$ & \\
\hline Cs-A + ALG or mAb \pm PDN & 33 & 4 & 15 & $(1-29)$ & \\
\hline T-cell depletion & 19 & 3 & 16 & $(0-32)$ & \\
\hline \multicolumn{6}{|l|}{ GVHD prophylaxis } \\
\hline Cs-A + MTX + ALG or mAb & 104 & 39 & 42 & $(31-52)$ & .0001 \\
\hline Other prophylaxis & 592 & 134 & 24 & $(21-28)$ & \\
\hline Cell dose infused & & & & & \\
\hline Less than $2 \times 10^{8} / \mathrm{kg}$ & 117 & 37 & 35 & $(26-44)$ & .09 \\
\hline $2 \times 10^{8} / \mathrm{kg}$ or more & 556 & 132 & 25 & $(21-29)$ & \\
\hline Unknown & 23 & 4 & & & \\
\hline Acute GVHD grade & & & & & \\
\hline Grade 0-I & 406 & 54 & 14 & $(11-18)$ & .0001 \\
\hline Grade II-IV & 290 & 119 & 45 & $(39-51)$ & \\
\hline
\end{tabular}

*The impact of parity on cGVHD occurrence was evaluated in the 117 donorrecipient pairs with a female donor older than 20 years; data on parity were available for 71 of these 117 donors (61\%). 
Table 3. Multivariate analysis of risk factors for cGVHD development

\begin{tabular}{|c|c|c|c|}
\hline & \multicolumn{3}{|c|}{ Multivariate analysis } \\
\hline & $\mathrm{RR}$ & $(95 \% \mathrm{Cl})$ & $P$ \\
\hline \multicolumn{4}{|l|}{ Patient age } \\
\hline Younger than $5 \mathrm{y}$ & 1.00 & & \\
\hline $5-15 y$ & 1.39 & $(0.93-2.08)$ & .1 \\
\hline 15 y or older & 1.82 & $(1.06-3.12)$ & .03 \\
\hline \multicolumn{4}{|l|}{ Donor age } \\
\hline Younger than $5 \mathrm{y}$ & 1.00 & & \\
\hline $5-20 y$ & 3.26 & $(1.57-6.77)$ & .001 \\
\hline 20 y or older & 5.73 & $(2.56-12.8)$ & .0001 \\
\hline \multicolumn{4}{|l|}{ Sex } \\
\hline Female donor and male recipient vs others & 1.52 & $(1.11-2.07)$ & .01 \\
\hline \multicolumn{4}{|l|}{ Diagnosis } \\
\hline Malignant vs nonmalignant & 1.80 & $(1.13-2.88)$ & .01 \\
\hline \multicolumn{4}{|l|}{ Donor } \\
\hline HLA-identical family vs other donors & .69 & $(0.41-1.17)$ & NS \\
\hline \multicolumn{4}{|l|}{ Stem cell source } \\
\hline $\mathrm{CB}$ vs bone marrow + peripheral blood & .07 & $(0.03-0.16)$ & .0001 \\
\hline \multicolumn{4}{|l|}{ Conditioning regimen } \\
\hline TBI vs chemotherapy & 1.56 & $(1.08-2.26)$ & .02 \\
\hline \multicolumn{4}{|l|}{ GVHD prophylaxis } \\
\hline \multicolumn{4}{|l|}{ Cs-A + MTX $+A L G$ or mAb vs other } \\
\hline prophylaxis & 1.55 & $(0.92-2.51)$ & .08 \\
\hline \multicolumn{4}{|l|}{ Acute GVHD grade } \\
\hline Grade II-IV vs grade $0-I$ & 2.14 & $(1.78-2.59)$ & .0001 \\
\hline
\end{tabular}

cause of death in 102 patients, whereas 89 children died of transplant-related causes. In patients with cGVHD, we observed a significantly higher percentage of transplant-related deaths $(69 \%)$ as compared to subjects without cGVHD (40\%), and a lower percentage of deaths due to disease progression ( $31 \%$ versus $60 \%, P=.0006)$. In the group of children who had cGVHD, this complication was indicated as the primary cause of death in 11 of the 31 patients who died due to transplant-related causes (35\%), so that $6 \%$ of the 173 patients with cGVHD died because of this complication.

In the 11 cases where cGVHD was reported as the main cause of death, the ultimate cause of death was bronchiolitis obliterans in 4 cases, cytomegalovirus interstitial pneumonia in 1 case, bacterial pneumonia in 1 case, other bacterial infections in 3 cases, hemorrhagic complications in 1 case, and multiorgan failure in 1 case.

For patients treated for nonmalignant disorders, the cumulative probability of TRM was $13 \%$ (95\% CI, 7\%-19\%) for children without cGVHD, $5 \%(95 \%$ CI, $0 \%-15 \%)$ for those with the limited form of the disease, and 64\% (95\% CI, 11\%-100\%) for those with extensive cGVHD $(P=.016)$. For subjects treated for malignant diseases, the cumulative probability of TRM was $9 \%(95 \% \mathrm{CI}$, $5 \%-13 \%)$ for children without cGVHD, $15 \%$ (95\% CI, 5\%-25\%) for those with limited disease, and 24\% (95\% CI, 12\%-36\%) for those with extensive cGVHD $(P=.036)$.

\section{Relapse probability}

Of the 450 children who underwent HSCT for treatment of hematologic malignancy, 127 (28\%) experienced disease relapse. Analyzing the risk of relapse according to cGVHD occurrence, we observed that the 6-year cumulative relapse probability was significantly lower $(P=.0001)$ in children with cGVHD, being $16 \%(95 \%$ CI, $10 \%-22 \%)$ compared with a value of $39 \%$ (95\% CI, $33 \%-45 \%$ ) in patients without cGVHD (Figure 3).

Tables 5 and 6 show the results of univariate and multivariate analysis of the probability of relapse in the 450 children affected by hematologic malignancies. cGVHD confirmed its protective effect
Table 4. Causes of death for patients with and without cGVHD

\begin{tabular}{|c|c|c|c|}
\hline & $\begin{array}{c}\text { No chronic } \\
\text { GVHD } \\
\text { (523 patients) }\end{array}$ & $\begin{array}{c}\text { Chronic } \\
\text { GVHD } \\
\text { (173 patients) }\end{array}$ & $\begin{array}{c}\text { Total } \\
\text { (696 patients) }\end{array}$ \\
\hline Disease progression (\%) & $88(60)$ & $14(31)$ & $102(53)$ \\
\hline Transplant-related causes (\%) & $58(40)$ & $31(69)$ & $89(47)$ \\
\hline Bacterial pneumonia & 5 & 3 & \\
\hline HCMV interstitial pneumonia & 2 & 0 & \\
\hline Bacterial infection & 10 & 5 & \\
\hline Fungal infection & 4 & 4 & \\
\hline Viral infection & 0 & 1 & \\
\hline EBV-PTLD & 2 & 0 & \\
\hline Encephalitis & 2 & 0 & \\
\hline ARDS & 5 & 1 & \\
\hline Idiopathic interstitial pneumonia & 5 & 1 & \\
\hline Autoimmune hemolytic anemia & 2 & 0 & \\
\hline \multicolumn{4}{|l|}{ Thrombotic thrombocytopenic } \\
\hline purpura & 2 & 0 & \\
\hline Liver failure & 2 & 0 & \\
\hline Renal failure & 0 & 1 & \\
\hline Cardiac insufficiency & 1 & 0 & \\
\hline Multiorgan failure & 6 & 2 & \\
\hline Hemorrhage & 10 & 2 & \\
\hline cGVHD & 0 & 11 & \\
\hline Total & 146 & 45 & 191 \\
\hline
\end{tabular}

$\chi^{2}=11.76, P=.0006$ for the comparison of causes of death (disease progression versus transplant-related cause) in subjects with and without cGVHD.

For the 11 patients with cGVHD reported as the main cause of death, the ultimate cause of death was bronchiolitis obliterans in 4 cases, HCMV interstitial pneumonia in 1 case, bacterial pneumonia in 1 case, other bacterial infections in 3 cases, hemorrhagic complications in 1 case, and multiorgan failure in 1 case. HCMV indicates human cytomegalovirus; EBV-PTLD, Epstein-Barr virus-related posttransplantation lymphoproliferative disease; ARDS, acute respiratory distress syndrome.

against relapse also in multivariate analysis $(\mathrm{RR}=0.32, P=.0001$, for patients with cGVHD versus those without cGVHD).

Stratifying the analysis by type of malignancy, we observed that the GVL effect associated with cGVHD was stronger in the 268 patients with ALL. In fact, the relapse probability for children with ALL and cGVHD was 14\% (95\% CI, 6\%-21\%) compared with the $47 \%$ (95\% CI, 39\%-54\%) observed in children with ALL but without $\mathrm{cGVHD}(P=.0001)$. On the contrary, for the 99 patients with AML, the relapse probability was identical $(29 \%)$ in both groups of patients. Among the 20 children with MDS, development of cGVHD was associated with a lower relapse probability, even

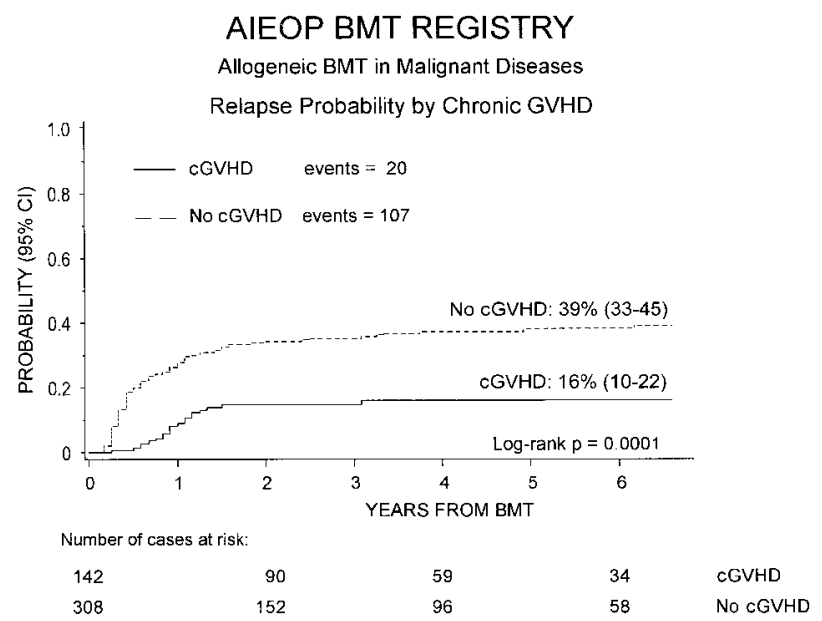

Figure 3. Six-year relapse probability after HSCT for children affected by hematologic malignancies, according to cGVHD development. Patients experiencing cGVHD had a significantly lower risk of relapse $(P=.0001)$. 
Table 5 . Univariate analysis of relapse probability in the $\mathbf{4 5 0}$ patients with malignant disease

\begin{tabular}{|c|c|c|c|c|c|}
\hline & \multicolumn{5}{|c|}{ Univariate analysis } \\
\hline & $\begin{array}{c}\text { Number of } \\
\text { cases }\end{array}$ & Events & $\begin{array}{c}\text { Probability, } \\
\%\end{array}$ & $(95 \% \mathrm{Cl})$ & $P$ \\
\hline \multicolumn{6}{|l|}{ Patient age } \\
\hline Younger than $5 y$ & 110 & 30 & 28 & $(20-37)$ & NS \\
\hline $5-10 y$ & 174 & 51 & 34 & $(26-41)$ & \\
\hline $10-15 y$ & 125 & 32 & 29 & $(20-38)$ & \\
\hline 15 y or older & 41 & 14 & 41 & $(22-60)$ & \\
\hline \multicolumn{6}{|l|}{ Donor age } \\
\hline Younger than $5 y$ & 81 & 23 & 31 & $(20-42)$ & NS \\
\hline $5-10 y$ & 95 & 24 & 27 & $(17-36)$ & \\
\hline $10-15 y$ & 64 & 18 & 33 & $(19-46)$ & \\
\hline $15-20 y$ & 55 & 14 & 28 & $(15-40)$ & \\
\hline $20-30 y$ & 69 & 22 & 34 & $(23-46)$ & \\
\hline $30-40 y$ & 56 & 17 & 37 & $(21-52)$ & \\
\hline 40 y or older & 30 & 9 & 44 & $(15-72)$ & \\
\hline \multicolumn{6}{|l|}{ Sex } \\
\hline \multicolumn{6}{|l|}{ Female donor and male } \\
\hline recipient & 103 & 20 & 21 & $(13-29)$ & .0706 \\
\hline Other & 320 & 90 & 32 & $(26-38)$ & \\
\hline \multicolumn{6}{|l|}{ Diagnosis } \\
\hline ALL & 268 & 87 & 35 & $(29-41)$ & NS \\
\hline AML & 99 & 24 & 31 & $(19-42)$ & \\
\hline MDS & 36 & 8 & 25 & $(10-40)$ & \\
\hline CML & 28 & 3 & 18 & $(0-39)$ & \\
\hline Lymphoma & 19 & 5 & 28 & $(7-49)$ & \\
\hline \multicolumn{6}{|l|}{ Disease phase } \\
\hline Early & 285 & 66 & 26 & $(21-32)$ & .0003 \\
\hline Advanced & 165 & 61 & 42 & $(34-51)$ & \\
\hline \multicolumn{6}{|l|}{ Donor } \\
\hline HLA-identical family & 306 & 85 & 30 & $(25-36)$ & NS \\
\hline Other donor & 144 & 42 & 36 & $(26-46)$ & \\
\hline \multicolumn{6}{|l|}{ Stem cell source } \\
\hline \multicolumn{6}{|l|}{ Bone marrow + peripheral } \\
\hline blood & 434 & 121 & 31 & $(26-36)$ & NS \\
\hline Cord blood & 16 & 6 & 52 & $(19-85)$ & \\
\hline \multicolumn{6}{|l|}{ GVHD prophylaxis } \\
\hline Cs-A + MTX + ALG or mAb & 81 & 25 & 34 & $(23-45)$ & NS \\
\hline Other prophylaxis & 369 & 102 & 31 & $(26-36)$ & \\
\hline \multicolumn{6}{|l|}{ Conditioning regimen } \\
\hline Chemotherapy based & 148 & 41 & 33 & $(24-43)$ & NS \\
\hline TBI based & 302 & 86 & 31 & $(26-37)$ & \\
\hline \multicolumn{6}{|l|}{ Acute GVHD } \\
\hline $0-1$ & 223 & 77 & 38 & $(31-45)$ & .0005 \\
\hline II-IV & 227 & 49 & 25 & $(18-31)$ & \\
\hline \multicolumn{6}{|l|}{ Chronic GVHD } \\
\hline Absent & 308 & 107 & 39 & $(33-45)$ & .0001 \\
\hline Present & 142 & 20 & 16 & $(9-22)$ & \\
\hline \multicolumn{6}{|l|}{ Chronic GVHD } \\
\hline Absent & 308 & 107 & 39 & $(33-45)$ & .0001 \\
\hline Limited & 89 & 16 & 20 & $(11-28)$ & \\
\hline Extensive & 53 & 4 & 10 & $(0-19)$ & \\
\hline
\end{tabular}

though the advantage was not statistically significant $(0 \%$ versus $36 \%, P=.053$ ). Because only 3 of the 28 children with CML experienced a relapse, it was impossible to analyze the role of cGVHD on leukemia recurrence in this group of patients.

\section{Survival and DFS}

Overall, 482 of the 696 patients analyzed (69\%) are alive and disease free, with a cumulative probability of DFS of $67 \%$ (95\% CI, 63\%-71\%).

Figure 4 shows the 6-year cumulative probability of DFS for
Table 6. Multivariate analysis of relapse probability in the $\mathbf{4 5 0}$ patients with malignant disease

\begin{tabular}{lccc}
\hline & \multicolumn{3}{c}{ Multivariate analysis } \\
\cline { 2 - 4 } & $\mathrm{RR}$ & $(95 \% \mathrm{Cl})$ & $P$ \\
\hline $\begin{array}{l}\text { Sex } \\
\quad \text { Female donor and male recipient vs others }\end{array}$ & 0.82 & $(0.56-1.21)$ & $\mathrm{NS}$ \\
$\begin{array}{l}\text { Disease phase } \\
\quad \text { Advanced vs early }\end{array}$ & 2.11 & $(1.48-3.00)$ & .0001 \\
$\begin{array}{l}\text { Acute GVHD } \\
\quad \text { II-IV vs 0-I }\end{array}$ & 0.91 & $(0.65-1.27)$ & $\mathrm{NS}$ \\
$\begin{array}{l}\text { CGVHD } \\
\quad \text { Present vs absent }\end{array}$ & 0.32 & $(0.20-0.52)$ & .0001 \\
\hline
\end{tabular}

Variables with $P<.1$ in univariate analysis were included in the multivariate analysis.

patients with either nonmalignant disorders (Figure 4A) or hematologic malignancies (Figure 4B), respectively. For children with nonmalignant diseases, no statistically significant difference was observed for DFS between patients without or with cGVHD (85\% versus $77 \%, P=\mathrm{NS}$ ), this finding being due to the fact that most of patients with cGVHD had the limited form of the disease. On the
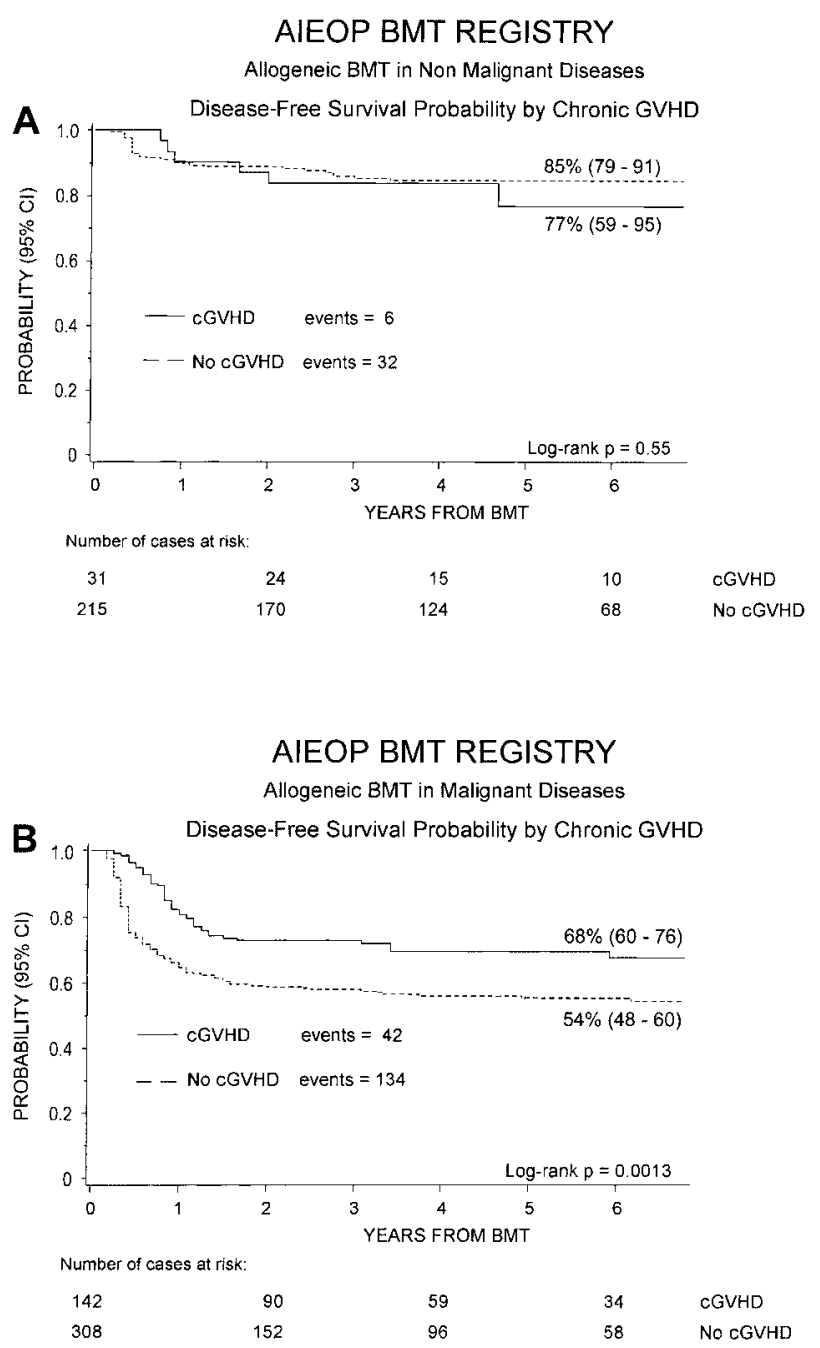

Figure 4. Probability of DFS. Six-year probability of DFS according to the development of cGVHD is shown for patients affected by nonmalignant disorders $(A)$ and for those affected by hematologic malignancies (B). The difference was not statistically significant for nonmalignant disorders, whereas in the group of patients affected by malignant diseases, the advantage for subjects with cGVHD was statistically significant $(P=.0013)$. 
contrary, considering children receiving transplants for malignant diseases, patients who developed cGVHD had a significantly better DFS, as compared to children without cGVHD (68\% versus $54 \%$, $P=$.0013).

Tables 7 and 8 summarize the results of univariate and multivariate analysis of DFS probability for the 450 children affected by malignant diseases. As for relapse, the positive impact of cGVHD on DFS was confirmed also in multivariate analysis, where this variable was associated with a relative risk of DFS of $2.07(P=.0001)$.

Table 7. Univariate analysis of DFS probability in the $\mathbf{4 5 0}$ patients with malignant disease

\begin{tabular}{|c|c|c|c|c|c|}
\hline & \multicolumn{5}{|c|}{ Univariate analysis } \\
\hline & $\begin{array}{l}\text { No. of } \\
\text { cases }\end{array}$ & Events & $\begin{array}{c}\text { Probability, } \\
\%\end{array}$ & $(95 \% \mathrm{Cl})$ & $P$ \\
\hline \multicolumn{6}{|l|}{ Patient age } \\
\hline Younger than $5 \mathrm{y}$ & 110 & 35 & 66 & $(56-76)$ & NS \\
\hline $5-10 y$ & 174 & 72 & 57 & $(49-64)$ & \\
\hline $10-15 y$ & 125 & 52 & 57 & $(48-66)$ & \\
\hline 15 y or older & 41 & 17 & 54 & $(35-72)$ & \\
\hline \multicolumn{6}{|l|}{ Donor age } \\
\hline Younger than $5 \mathrm{y}$ & 81 & 31 & 61 & $(50-72)$ & .09 \\
\hline $5-0 y$ & 95 & 31 & 65 & $(55-76)$ & \\
\hline $10-15 y$ & 64 & 22 & 63 & $(49-76)$ & \\
\hline $15-20 y$ & 55 & 18 & 65 & $(52-78)$ & \\
\hline $20-30$ y & 69 & 32 & 52 & $(40-64)$ & \\
\hline $30-40 y$ & 56 & 24 & 48 & $(34-62)$ & \\
\hline 40 y or older & 30 & 14 & 45 & $(21-70)$ & \\
\hline \multicolumn{6}{|l|}{ Sex } \\
\hline \multicolumn{6}{|l|}{ Female donor and male } \\
\hline recipient & 103 & 53 & 59 & $(50-67)$ & NS \\
\hline Other & 320 & 123 & 59 & $(53-65)$ & \\
\hline \multicolumn{6}{|l|}{ Diagnosis } \\
\hline ALL & 268 & 116 & 56 & $(50-62)$ & NS \\
\hline AML & 99 & 30 & 64 & $(53-76)$ & \\
\hline MDS & 36 & 15 & 54 & $(35-73)$ & \\
\hline CML & 28 & 8 & 66 & $(45-87)$ & \\
\hline Lymphoma & 19 & 7 & 63 & $(41-85)$ & \\
\hline \multicolumn{6}{|l|}{ Disease phase } \\
\hline Early & 285 & 93 & 65 & $(59-71)$ & .0001 \\
\hline Advanced & 165 & 83 & 48 & $(39-56)$ & \\
\hline \multicolumn{6}{|l|}{ Donor } \\
\hline HLA-identical family & 306 & 103 & 65 & $(59-70)$ & .0003 \\
\hline Other donors & 144 & 73 & 45 & $(34-55)$ & \\
\hline \multicolumn{6}{|l|}{ Stem cell source } \\
\hline \multicolumn{6}{|l|}{ Bone marrow + peripheral } \\
\hline blood & 434 & 167 & 59 & $(54-64)$ & .1032 \\
\hline Cord blood & 16 & 9 & 38 & $(9-66)$ & \\
\hline \multicolumn{6}{|l|}{ GVHD prophylaxis } \\
\hline Cs-A + MTX + ALG or mAb & 81 & 39 & 51 & $(39-62)$ & .0533 \\
\hline Other prophylaxis & 369 & 167 & 61 & $(55-66)$ & \\
\hline \multicolumn{6}{|l|}{ Conditioning regimen } \\
\hline Chemotherapy based & 148 & 52 & 59 & $(50-69)$ & NS \\
\hline TBI based & 302 & 124 & 58 & $(52-64)$ & \\
\hline \multicolumn{6}{|l|}{ Acute GVHD } \\
\hline $0-1$ & 223 & 89 & 58 & $(51-65)$ & NS \\
\hline II-IV & 227 & 87 & 60 & $(53-67)$ & \\
\hline \multicolumn{6}{|l|}{ cGVHD } \\
\hline Absent & 308 & 134 & 55 & $(49-60)$ & .0013 \\
\hline Present & 142 & 42 & 68 & $(60-76)$ & \\
\hline \multicolumn{6}{|l|}{ cGVHD } \\
\hline Absent & 308 & 134 & 55 & $(49-60)$ & .0055 \\
\hline Limited & 89 & 26 & 68 & $(58-79)$ & \\
\hline Extensive & 53 & 16 & 68 & $(54-81)$ & \\
\hline
\end{tabular}

Table 8. Multivariate analysis of DFS probability in the 450 patients with malignant disease

\begin{tabular}{llll}
\hline & \multicolumn{3}{c}{ Multivariate analysis } \\
\cline { 2 - 4 } & $\mathrm{RR}$ & $(95 \% \mathrm{Cl})$ & $P$ \\
\hline $\begin{array}{l}\text { Donor age } \\
\quad \text { Younger than 20 y vs 20 y or older }\end{array}$ & 1.23 & $(0.79-1.90)$ & $\mathrm{NS}$ \\
$\begin{array}{l}\text { Disease phase } \\
\quad \text { Advanced vs early }\end{array}$ & 0.57 & $(0.42-0.78)$ & .0004 \\
$\begin{array}{l}\text { Donor } \\
\text { HLA-identical family vs other donors }\end{array}$ & 1.52 & $(0.95-2.43)$ & .08 \\
$\begin{array}{l}\text { GVHD prophylaxis } \\
\quad \text { Cs-A + MTX + ALG or mAb vs other prophylaxis }\end{array}$ & .97 & $(0.58-1.64)$ & $\mathrm{NS}$ \\
$\begin{array}{l}\text { CGVHD } \\
\quad \text { Present vs absent }\end{array}$ & & & \\
\end{tabular}

Variables with $P<.1$ in univariate analysis were included in the multivariate analysis.

As already observed for relapse probability, also for DFS the favorable influence of cGVHD was observed only for children with ALL, where the cumulative probability of DFS was $74 \%$ (95\% CI, 64\%-83\%) for patients developing cGVHD and 47\% (95\% CI, $38 \%-53 \%)$ for children without cGVHD $(P=.0001)$, whereas the effect on other hematologic malignancies was nonsignificant. In fact, in the 99 patients with AML, the DFS probability was $59 \%$ (95\% CI, 36\%-82\%) for children with cGVHD and 68\% for those without cGVHD $(P=\mathrm{NS})$, and in the 28 children with CML it was $64 \%$ (95\% CI, 35\%-92\%) and 71\% (95\% CI, 44\%-97\%) for subjects with and without cGVHD, respectively $(P=\mathrm{NS})$. Finally, also considering the 20 children with MDS, the outcome of patients with and without cGVHD was similar, DFS being 67\% (95\% CI, $36 \%-97 \%$ ) and 64\% (95\% CI, 35\%-92\%), respectively ( $P=\mathrm{NS}$ ).

\section{Discussion}

Chronic GVHD remains a substantial problem of allogeneic HSCT. Several studies, published in recent years, introduced the notion that recipient age is a major risk factor for the development of cGVHD and that children have a lower probability of presenting this complication. ${ }^{4-6}$ However, this information, as well as our clinical knowledge of cGVHD and of its risk factors, are based primarily on results of analyses performed in adults.

In our study, conducted on the largest pediatric population reported so far, we observed a cumulative probability of cGVHD of $27 \%$, which is similar to probabilities ranging from $22 \%$ to $29 \%$ reported by 3 other analyses conducted on smaller cohorts of pediatric patients in recent years. ${ }^{13-15}$ This probability is nearly half of the estimated probability of $40 \%$ to $50 \%$ described in adults. ${ }^{4-6}$ In our group of patients younger than 18 years, older patient and donor age were predictive of a higher risk of cGVHD both in univariate and in multivariate analysis. On the other hand, the type of donor and of GVHD prophylaxis was not predictive of the development of this complication. In multivariate analysis, other factors, such as the female donor-male recipient combination, a diagnosis of malignant disease, the use of TBI, and, as expected, previous grade II to IV acute GVHD, were characterized by a significantly higher risk of cGVHD. Furthermore, in agreement with the observation of Rocha et al, ${ }^{30}$ use of $\mathrm{CB}$ progenitor cells was confirmed to be characterized by a very low probability of cGVHD. In contrast, we could not confirm the observation of an increased risk of cGVHD in subjects receiving peripheral blood stem cells. ${ }^{8,9}$ This was possibly due to the limited number of patients receiving peripheral blood stem cells. 
Our study confirms previously published reports documenting that male patients given a transplant from a female donor experience more GVHD, ${ }^{6}$ an observation that has been biologically explained hypothesizing that male antigens (ie, $\mathrm{H}-\mathrm{Y}$ ) not shared by females are recognized and attacked by the donor's immune system. ${ }^{31,32}$ However, our data are particularly intriguing because most female donors were young and, thus, not sensitized toward male antigens by previous pregnancies. Furthermore, even if evaluated on a limited number of subjects, parity of female donors was not a risk factor for cGVHD development; this suggests that even a primary immune response toward these molecules may produce cGVHD.

Children with nonmalignant disorders had a reduced risk of developing cGVHD. Several factors may be considered to explain this observation. Because children with these diseases do not benefit at all from GVHD, it is reasonable to hypothesize that the most effective pharmacologic strategies for both GVHD prevention and therapy of acute GVHD were used in these patients. Moreover, it has been already reported that these patients can have a mixed chimerism, ${ }^{33-35}$ and this condition is associated with reduced susceptibility to GVHD, probably through mechanisms of central tolerance with negative selection of both host-reactive and donor-reactive T cells. ${ }^{36}$ Finally, some of the children with nonmalignant disorders (ie, those with aplastic anemia or with congenital immunodeficiencies) were given less intensive preparative regimens and it has been hypothesized that the cytokine storm, which is dependent on the intensity of the conditioning regimen, triggers development of GVHD. ${ }^{37}$ In this regard, the finding of an increased risk of cGVHD in children given TBI as part of the preparative regimen is also of particular interest. Moreover, because it has been suggested as a relevant role of recipient's thymus in promoting tolerance of donor cells, we speculate that the higher risk of cGVHD in children given TBI can be partly explained by a radiation-induced damage to thymic epithelial cells..$^{38-40}$

We also found an increased risk of cGVHD in patients receiving a transplant from an older donor. The detrimental effect of increased donor age on cGVHD has been recently reported in a cohort of patients given HSCT from unrelated volunteers. ${ }^{41}$ The biologic mechanisms accounting for this effect of donor age remain unclear and deserve further investigation.

Considerable experimental and clinical data suggest a role of the immune system in controlling cancer and, particularly, leukemia, through the GVL effect. ${ }^{12,42-45}$ In our study, we document a strong protective effect of cGVHD against relapse in children with ALL, whereas the advantage was lower and not statistically significant for patients with MDS and absent for those with AML. Moreover, in children with ALL, the increased TRM associated with cGVHD was largely offset by the impressive reduction in relapse probability, thus resulting in a significantly better survival and DFS.

Despite a beneficial GVL effect against relapse, cGVHD remains a major determinant of poor long-term outcome and of impaired quality of life after allogeneic HSCT. ${ }^{2}$ For this reason, several efforts have been made to identify factors having an unfavorable prognostic significance, to select subjects with higher risk of either death or invalidating sequelae (as severe joint contractures requiring physical therapy, impairment of lung function, keratoconjunctivitis sicca with corneal lesions, malnutrition due to gastrointestinal involvement), who need to be treated promptly and more intensively. ${ }^{46-49}$ Over the last few years, new drugs and different treatment modalities have been developed for patients with cGVHD, ${ }^{50}$ even though the optimal treatment is still controversial and no single therapy has been demonstrated to be superior and most effective..$^{51}$

In our study population, subjects developing cGVHD had a significantly higher TRM, as compared to those without the disease, even though only $6 \%$ of children with cGVHD died directly or indirectly because of this complication. The negative effect of cGVHD was particularly evident in patients with the extensive form of the disease and for those affected by nonmalignant disorders. These observations emphasize the need for a more effective prophylaxis for patients undergoing transplantation with the aim of curing nonmalignant disorders and a more effective treatment for those with extensive GVHD or with poor prognostic clinical features.

Our data document that children have a lower incidence of cGVHD compared with adults. Use of CB stem cells and of conditioning regimens without TBI, as well as better strategies for preventing acute GVHD occurrence, could further decrease the risk of this complication. We provide evidence for a strong antileukemia effect of cGVHD for ALL, but not for other hematologic malignancies. Despite an increased TRM, the probability of DFS in ALL was not impaired by the occurrence of this complication.

\section{Acknowledgment}

We would like to thank Nicoletta Sacchi, at the Italian Bone Marrow Donor Registry, for the help in collecting part of the data on parity of female donors.

\section{References}

1. Atkinson K. Chronic graft-versus-host disease. Bone Marrow Transplant. 1990;5:69-82.

2. Deeg HJ, Leisenring W, Storb R, et al. Long-term outcome after marrow transplantation for severe aplastic anemia. Blood. 1998;91:3637-3645.

3. Kulkarni S, Powles R, Treleaven J, et al. Chronic graft versus host disease is associated with longterm risk for pneumococcal infections in recipients of bone marrow transplants. Blood. 2000;95 3683-3686.

4. Atkinson K, Horowitz MM, Gale RP, et al. Risk factors for chronic graft-versus-host disease after HLA-identical sibling bone marrow transplantation. Blood. 1990;75:2459-2464.

5. Ochs LA, Miller WJ, Filipovich AH, et al. Predictive factors for chronic graft-versus-host disease after histocompatible sibling donor bone marrow transplantation. Bone Marrow Transplant. 1994; 13:455-460.
6. Carlens S, Ringdén O, Remberger M, et al. Risk factors for chronic graft-versus-host disease after bone marrow transplantation: a retrospective single centre analysis. Bone Marrow Transplant. 1998;22:755-761.

7. Marks DI, Cullis JO, Ward KN, Lacey S, Syzdlo $R$, Hughes TP. Allogeneic bone marrow transplantation for chronic myeloid leukemia using sibling and volunteer unrelated donors: a comparison of complications in the first 2 years. Ann Intern Med. 1993;119:207-214.

8. Cutler C, Giri S, Jeyapalan S, Paniagua D, Viswanathan A, Antin JH. Acute and chronic graftversus-host disease after allogeneic peripheral-blood stem-cell and bone marrow transplantation: a metaanalysis. J Clin Oncol. 2001;19:3685-3691.

9. Przepiorka D, Anderlini P, Saliba R, et al. Chronic graft-versus-host disease after allogeneic blood stem cell transplantation. Blood. 2001;98:1695-1700.
10. Ringdén O, Labopin M, Gluckman E, et al. Strong antileukemic effect of chronic graft-versus-host disease in allogeneic marrow transplant recipients having acute leukemia treated with methotrexate and cyclosporine. Transplant Proc. 1997; 29:733-734.

11. Zikos P, Van-Lint MT, Lamparelli T, et al. Allogeneic hemopoietic stem cell transplantation for patients with high risk acute lymphoblastic leukemia: favorable impact of chronic graft-versus-host disease on survival and relapse. Haematologica. 1998;83:896-903.

12. Brunet S, Urbano-Ispizua A, Ojeda E, et al. Favourable effect of the combination of acute and chronic graft-versus-host disease on the outcome of allogeneic peripheral blood stem cell transplantation for advanced haematological malignancies. Br J Haematol. 2001;114:544-550. 
13. Locatelli F, Uderzo C, Dini G, et al. Graft-versushost disease in children: the AIEOP-BMT Group experience with cyclosporin A. Bone Marrow Transplant. 1993;12:627-633.

14. Eisner MD, August CS. Impact of donor and recipient characteristics on the development of acute and chronic graft-versus-host disease following pediatric bone marrow transplantation. Bone Marrow Transplant. 1995;15:663-668.

15. Kondo M, Kojima S, Horibe K, Kato K, Matsuyama T. Risk factors for chronic graft-versushost disease after allogeneic stem cell transplantation in children. Bone Marrow Transplant. 2001; 27:727-730.

16. Gilliam AC, Murphy GF. Cellular pathology of cutaneous graft-versus-host disease. In: Ferrara JL, Deeg HJ, Burakoff SJ, eds. Graft-vs.-Host Disease. New York, NY: Marcel Dekker; 1997:291313.

17. Crawford JM. Graft-versus-host disease of the liver. In: Ferrara JL, Deeg HJ, Burakoff SJ, eds. Graft-vs.-Host Disease. New York, NY: Marcel Dekker; 1997:315-336.

18. Mowat A. Intestinal graft-versus-host disease. In Ferrara JL, Deeg HJ, Burakoff SJ, eds. Graft-vs.Host Disease. New York, NY: Marcel Dekker 1997:337-384.

19. Glucksberg $H$, Storb $R$, Fefer A, et al. Clinica manifestations of graft-versus-host disease in human recipients of marrow from HL-A-matched sibling donors. Transplantation. 1974;18:295304.

20. Shulman $\mathrm{HM}$, Sullivan $\mathrm{KM}$, Weiden $\mathrm{PL}$, et al. Chronic graft-versus-host syndrome in man: a long-term clinicopathological study of 20 Seattle patients. Am J Med. 1980;69:204-217.

21. Ringdén O, Deeg HJ. Clinical spectrum of graftversus-host disease. In: Ferrara JL, Deeg HJ, Burakoff SJ, eds. Graft-vs.-Host Disease. New York, NY: Marcel Dekker; 1997:525-559.

22. Rossetti F, Zulian F, Dall'Amico R, Messina C, Montini G, Zacchello F. Extracorporeal photochemotherapy as single therapy for extensive, cutaneous, chronic graft-versus-host disease. Transplantation. 1995;59:149-151.

23. Salvaneschi L, Perotti C, Zecca M, et al. Extracorporeal photochemotherapy for treatment of acute and chronic GVHD in childhood. Transfusion. 2001:41:1299-1305.

24. Kaplan EL, Meier P. Nonparametral estimation from incomplete observations. J Am Stat Assoc. 1958;53:457-481.

25. Pepe MS, Longton G, Pettinger M, Mori M, Fisher LD, Storb R. Summarizing data on survival, relapse, and chronic graft-versus-host disease after bone marrow transplantation: motivation for and description of new methods. $\mathrm{Br} \mathrm{J}$ Haematol. 1993:83:602-607.
26. Pepe MS, Longton G, Thornquist M. A qualifier $\mathrm{Q}$ for the survival function to describe the prevalence of a transient condition. Sat Med. 1991;10: 413-421.

27. Byar DP. Identification of prognostic factors. In: Buyse ME, Staquet MJ, Sylvester RJ, eds. Cancer Clinical Trials: Methods and Practice. Oxford, United Kingdom: Oxford Medical Publications: 1988:423-443.

28. Cox DR. Regression models and life tables (with discussion). J Royal Stat Soc B. 1972;34:187202.

29. Klein JP, Rizzo JD, Zhang M-J, Keiding N. Statistical methods for the analysis and presentation of the results of bone marrow transplants. Vol 28. Part 2: regression modeling. Bone Marrow Transplant. 2001;1001-1011.

30. Rocha V, Wagner JE, Sobocinski KA, et al. Graftversus-host disease in children who have received a cord-blood or bone marrow transplant from an HLA-identical sibling. N Engl J Med. 2000;342:1846-1854.

31. Goulmy E, Termijtelen A, Bradley BA, van Rood JJ. Y-antigen killing by $T$ cells of women is restricted by HLA. Nature. 1977;266:544-545.

32. Goulmy E. Human minor histocompatibility antigens: new concepts for marrow transplantation and adoptive immunotherapy. Immunol Rev. 1997; 157:125-140.

33. Hill RS, Petersen FB, Storb R, et al. Mixed hematologic chimerism after allogeneic marrow transplantation for severe aplastic anemia is associated with a higher risk of graft rejection and a lessened incidence of acute graft-versus-host disease. Blood. 1986;67:811-816.

34. Andreani A, Manna M, Lucarelli G, et al. Persistence of mixed chimerism in patients transplanted for the treatment of thalassemia. Blood. 1996;87: 3494-3499.

35. Locatelli F, Bruno B, Zecca M, et al. Cyclosporin $A$ and short-term methotrexate versus cyclosporin $A$ as graft-versus-host disease prophylaxis in patients with severe aplastic anemia given allogeneic bone marrow transplantation from an HLA-identical sibling: results of a GITMO/EBMT randomized trial. Blood. 2000;96:1690-1697.

36. Sykes M, Eisenthal A, Sachs DH. Mechanism of protection from graft-vs-host disease in murine mixed allogeneic chimeras, I: development of a null cell population suppressive of cell-mediated lympholysis responses and derived from the syngeneic bone marrow component. J Immunol. 1988;140:2903-2911.

37. Ferrara JL, Deeg HJ. Graft-versus-host disease. N Engl J Med. 1991;324:667-674.

38. Beschorner WE, Di Gennaro KA, Hess AD, Santos GW. Cyclosporine and the thymus: influence of irradiation and age on thymic immunopathol- ogy and recovery. Cell Immunol. 1987:110:350 364

39. Shinozawa T, Beschorner WE, Hess AD. The thymus and prolonged administration of cyclosporine: irreversible immunopathologic changes associated with autologous pseudo-graft-versus-host disease. Transplantation. 1990;50:106-111.

40. Hess AD, Thoburn CJ. Immunobiology and immunotherapeutic implications of syngeneic/autologous graft-versus-host disease. Immunol Rev. 1997; 157:111-123.

41. Kollman C, Howe CWS, Anasetti C, et al. Donor characteristics as risk factors in recipients after transplantation of bone marrow from unrelated donors: the effect of age. Blood. 2001;98:2043 2051.

42. Weiden PL, Sullivan KM, Flournoy N, Storb R, Thomas ED. Antileukemic effect of chronic graftversus-host disease. N Engl J Med. 1981;304: 1529-1533.

43. Barrett AJ, van Rhee F. Graft-versus-leukaemia Baillieres Clin Haematol. 1997;10:337-355.

44. Locatelli F, Zecca M, Rondelli R, et al. Graft versus host disease prophylaxis with low-dose cyclosporine-A reduces the risk of relapse in children with acute leukemia given HLA-identical sibling bone marrow transplantation: results of a randomized trial. Blood. 2000;95:1572-1579.

45. Ringdén O, Labopin M, Gorin NC, et al. Is there a graft-versus-leukaemia effect in the absence of graft-versus-host disease in patients undergoing bone marrow transplantation for acute leukaemia? Br J Haematol. 2000;111:1130-1137.

46. Sullivan KM, Witherspoon RP, Storb R, et al. Prednisone and azathioprine compared with prednisone and placebo for treatment of chronic graft-v-host disease: prognostic influence of prolonged thrombocytopenia after allogeneic marrow transplantation. Blood. 1988;72:546-554.

47. Wingard JR, Piantadosi S, Vogelsang GB, et al Predictors of death from chronic graft-versus-host disease after bone marrow transplantation. Blood. 1989;74:1428-1435.

48. Sullivan KM, Shulman HM, Storb R, et al. Chronic graft-versus-host disease in 52 patients: adverse natural course and successful treatment with combination immunosuppression. Blood. 1981; 57:267-276.

49. Akpek G, Zahurak L, Piantadosi S, et al. Development of a prognostic model for grading chronic graft-versus-host disease. Blood. 2001;97:12191226.

50. Zecca M, Locatelli F. Management of graftversus-host disease in paediatric bone marrow transplant recipients. Paediatr Drugs. 2000;2:29 55

51. Vogelsang GB. How I treat chronic graft-versushost disease. Blood. 2001;97:1196-1201. 